\title{
Comparison of the passive microwave spectral signature of the Antarctic ice sheet with ground traverse data
}

\author{
Sylviane Surdyk ANd Michel Fily \\ Laboratoire de Glaciologie et de Géophysique de l'Environnement, CNRS, 38402 Saint-Martin d'Hères, France
}

\begin{abstract}
Scanning Multichannel Microwave Radiometer (SMMR) data are compared with the snow characteristics measured during several traverses over Antarctica including average density over $0-2 \mathrm{~m}, 10 \mathrm{~m}$ temperature, grain-size distributions and number of strata. First a local study of specified areas and then a global study show some strong dependence between satellite data and ground data. The polarization ratios are affected by the stratification of snow (number and nature of layers); large polarization ratios correspond to strong stratification, mainly for the lower frequencies. Because low density induces strong stratification there is also a dependence between polarization ratios and density even if the density is not the critical factor. The gradient ratios are linked to the grain-sizes as determined from detailed stratigraphies; the larger the grain-size, the smaller is the gradient ratio between 6.6 and $18 \mathrm{GHz}$.
\end{abstract}

\section{INTRODUCTION}

The large size of Antarctica and the harshness of its environment, with permanent stations essentially located on the coast, yield few ground measurements which can be used to validate satellite data. Yet many traverses were undertaken across Antarctica some twenty to thirty years ago during which many snow-cover measurements were made. These sets of data are useful in obtaining the variation of the near surface characteristics over long distances. In other respects, recent studies have shown that the large-scale spatial distribution of microwave brightness temperatures did not change appreciably during the eight years of SMMR data (Fily and Benoist, 1991). Therefore it is likely worthwhile to compare recent satellite data with the earlier traverse data: this is the objective of the research work presented here.

First, typical areas are selected from their distinct microwave signature, then the snow characteristics along representative traverses of these areas are analyzed and compared with satellite data. Finally the comparisons are made on a large scale with the global data set.

\section{DATA}

\section{Ground data}

In order to get a good spatial sampling over all the Antarctic ice sheet, a large set of ground data was compiled from 13 traverse data reports (Fig. 1). Four types of parameters were recorded which define the firn characteristics:

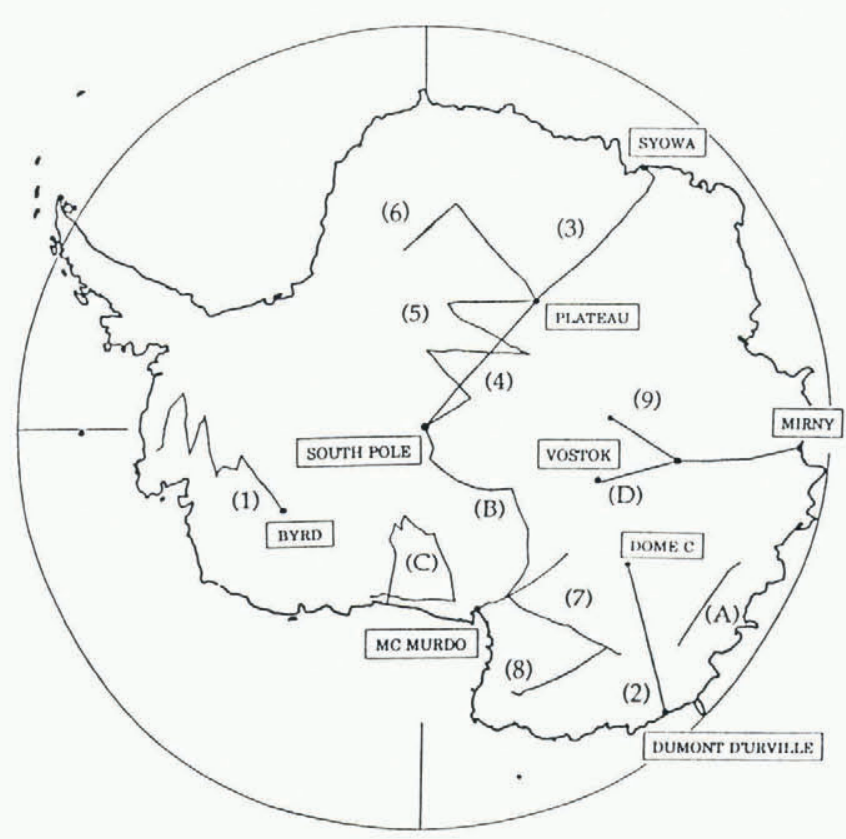

Fig. 1. Map of Antarctica, location of the 13 traverses: (1) Byrd-Elsworth mountain traverse (1960-61); (2) Dumont d'Urville-Dome C; (3) Syowa-South Pole traverse (1967-69); (4) Dronning Maud Land traverse I (1964-65); (5) Dronning Maud Land traverse II (1965-66); (6) Dronning Maud Land traverse III (1967-68); (7) Victoria Land traverse I (1958-59); (8) Victoria Land traverse II (1959-60); (9) MirnySovietskaya route; (A) Wilkes Land route $E$; (B) McMurdo-South Pole traverse (1960-61); (C) Ross Ice Shelf traverse (1957-58); (D) Mirny-Vostok route. 
1. Location (latitude, longitude and elevation): 467 data points.

2. Mean density over $0-2 \mathrm{~m}$ : 467 data points.

3. $10 \mathrm{~m}$ temperature, which is representative of the mean annual temperature: 272 data points.

4. Stratigraphy of $2 \mathrm{~m}$ deep snow pits with grain-size and number of strata: 118 data points.

Snow grains were classified according to their sizes, $\Phi$; four classes were chosen:

— fine grain-size, $\Phi<0.5 \mathrm{~mm}$, mean size $\Phi=0.2 \mathrm{~mm}$

- medium grain-size, $0.5 \leq \Phi<1 \mathrm{~mm}$, mean size $\Phi=$ $1.5 \mathrm{~mm}$

- coarse grain-size, $1 \leq \Phi<2 \mathrm{~mm}$, mean size $\Phi=$ $1.5 \mathrm{~mm}$

- very coarse grain-size, $\Phi \geq 2 \mathrm{~mm}$, mean size $\Phi=$ $3 \mathrm{~mm}$.

Grain-size distribution was computed for various depths: $0-0.3 \mathrm{~m}$ and $0-2 \mathrm{~m}$. Therefore a spatial distribution of grain-size is available and, also, a representation of the grain-size evolution over depth. In similar locations, firn properties measurements made during different traverses are consistent.

\section{SMMR data}

Microwave measurements were made using the Scanning Multichannel Microwave Radiometer, which measures radiation at five frequencies $(6.6,10.7,18,21$ and $37 \mathrm{GHz}$ ) at horizontal and vertical polarization with an incident angle of $50^{\circ}$. In this study, gridded data from November 1981 were used. The cell size is $150 \mathrm{~km}$, which corresponds to the $6.6 \mathrm{GHz}$ channel resolution ( $\mathrm{Fu}$ and others, 1988). The $21 \mathrm{GHz}$ channels did not operate as well as the other channels (Fu and others, 1988), so they were not used.

A bilinear type interpolation and a Spline smoothing were used to get the brightness temperatures for each traverse station.

Two parameters are used to study the spectral signature: the polarization difference and the frequency gradient. The use of ratios provides some independence with respect to surface temperature variations.

The polarization ratio is defined for each frequency as:

$$
\operatorname{PR}(\text { freq. })=\frac{\mathrm{TBv}(\text { freq. })-\mathrm{TBh}(\text { freq. })}{\mathrm{TBv}(\text { freq. })+\mathrm{TBh}\left(\text { freq }^{\prime}\right.}
$$

with $\mathrm{TBv}$ brightness temperature at vertical polarization and TBh brightness temperature at horizontal polarization.

The gradient ratio is

$$
\operatorname{GRi}(\text { freq. } 2-\text { freq.1 })=\frac{\operatorname{TBi}(\text { freq. } 2)-\mathrm{TBi}(\text { freq. } 1)}{\operatorname{TBi}(\text { freq. } 2)+\operatorname{TBi}(\text { freq. } 1)}
$$

with polarization i, vertical or horizontal.

In the following study, we use only the vertical gradient ratio, as the horizontal gradient ratio has almost the same evolution. The studied satellite parameters are $\mathrm{PR}(6.6), \mathrm{PR}(10.7), \mathrm{PR}(18)$ and $\mathrm{PR}(37)$ for the polariz- ation ratios and $\operatorname{GRv}(10.7-6.6), \operatorname{GRv}(18-6.6)$ and $\mathrm{GRv}(37-18)$ for the gradient ratios.

The highest frequency $37 \mathrm{GHz}$ has a weak penetration depth $(<1 \mathrm{~m}$ ) (Rott and others, 1985) and is therefore very dependent on the near surface snow. As the surface snow characteristics (roughness, crust, firn temperature) have an extreme temporal variability, we consider that comparison of the $37 \mathrm{GHz}$ SMMR data with much older surface measurements is difficult. Therefore, even if the $37 \mathrm{GHz}$ data are compared with the other channels, they are not used for the main conclusions. On the other hand, the variability of deep characteristics of snow is considered constant in time at least on a large scale. The lowest frequency channels are affected by those deep characteristics.

\section{LOCAL STUDY}

The spatial distribution of the microwave signature over the ice sheet reveals areas with typical spectral signatures. With the compiled ground data, the main snow characteristics are defined for each area.

\section{Determination of typical traverses}

From a principal component analysis, it was found that $\mathrm{PR}(6.6)$ and GRv(18-6.6) could be chosen as representative of the variability of the spectral signature (Fily and
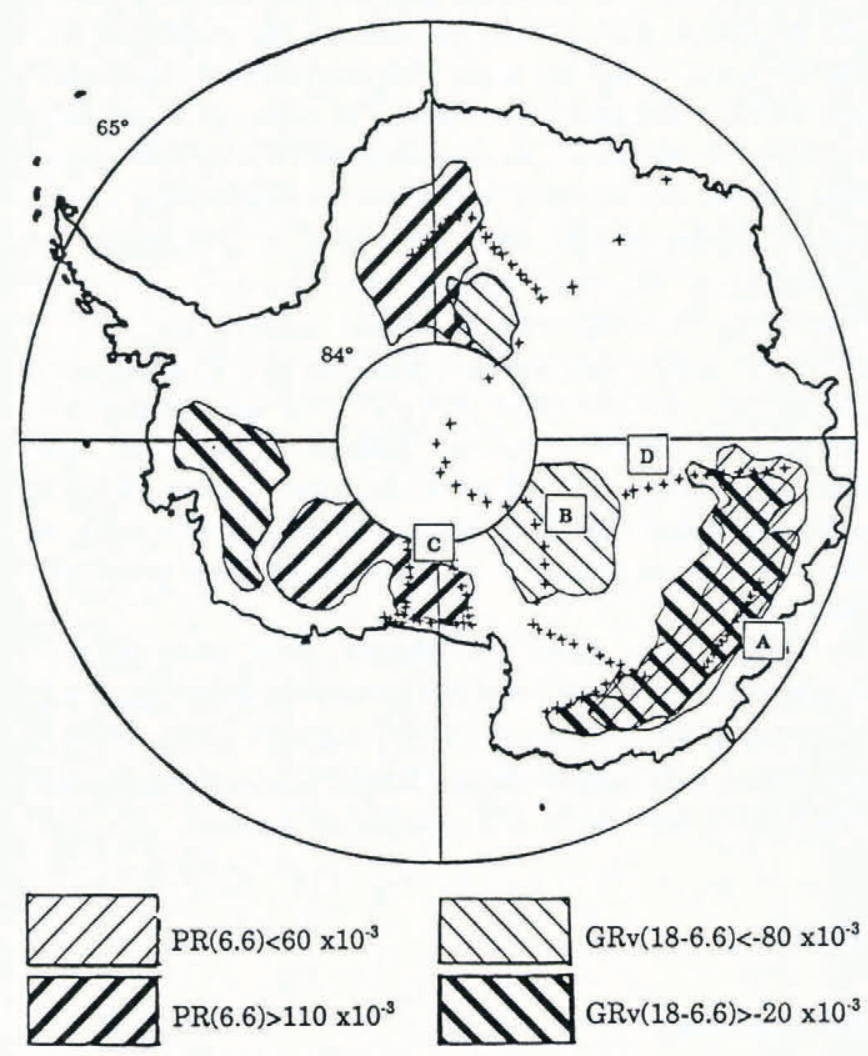

$+\quad$ Location of the stations

Fig. 2. Map of Antarctica with the extreme values of $P R(6.6)$ and $G R v(18-6.6)$ and the location of the stations with the most complete stratigraphy. 
(A)

(B)

(C)

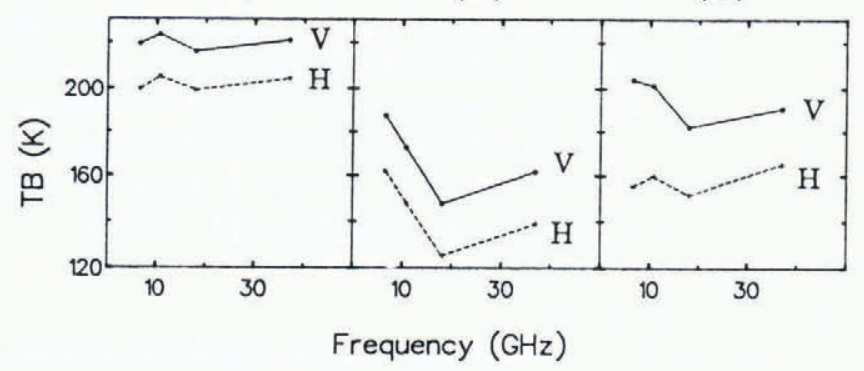

Fig. 3. Typical spectral signatures of the selected areas $(A),(B)$ and $(C)$.

Benoist, 1991). In Figure 2, areas of maximum and minimum values of $\mathrm{PR}(6.6)$ and $\mathrm{GRv}(18-6.6)$ and, also, the locations of the stations with the most complete stratigraphy are represented. From this map, four routes have been selected for further investigations (example of spectral signatures, Fig. 3): (A) Wilkes Land traverse, (B) McMurdo-South Pole traverse, (C) Ross Ice Shelf traverse, (D) Mirny-Vostok traverse.

\section{Description of the selected traverses}

\section{Wilkes Land traverse}

Measurements have been made during several traverses by Australian scientists since the year 1980 (Goodwin, $1988 \mathrm{a}, \mathrm{b})$. Stations are identified by the distance in kilometers from the starting point $\left(68.6^{\circ} \mathrm{S}, 113.3^{\circ} \mathrm{E}\right)$. Firn temper-ature decreases all along the route from $27^{\circ} \mathrm{C}$ to $-33^{\circ} \mathrm{C}$, whereas the elevation increases, starting at $1600 \mathrm{~m}$, going through a maximum of $2300 \mathrm{~m}$ at $500 \mathrm{~km}$ and ending at $2200 \mathrm{~m}$.

Density is higher than $420 \mathrm{~kg} \mathrm{~m}^{-3}$ for most of the traverse (Fig. 4a). There is a minimum at $500 \mathrm{~km}$, which corresponds to the maximum elevation. Grain-size in the stratigraphy shows no significant variation either on the surface all along the route $(0-30 \mathrm{~cm})$ or in depth $(0-2 \mathrm{~m})$ (Fig. 4a). The snow grains belong to the fine-medium grain-size class. The number of strata is of the order of 1520. This small number is due to the high snow accumulation rate in the coastal region (about $40 \mathrm{~g}$ $\mathrm{cm}^{-1} \mathrm{a}^{-1}$ (Bromwich, 1988)). Strong wind has an important impact on the snow surface and therefore on the stratigraphy in this area. Its mechanical action produces high surface roughness, building up sastrugi and forming wind crusts. The snow becomes compact with small grain-size and high density (Goodwin, 1988a, b).

Polarization ratios are constant and weak (about 40 $50 \times 10^{-3}$ ) along the traverse, and identical whatever the frequency (Fig. 4a). Gradient ratios are also constant and near zero. $\operatorname{GRv}(10.7-6.6)$ and $\operatorname{GRv}(37-18)$ are positive and $\operatorname{GRv}(18-6.6)$ is negative (Fig. 4a) all along the traverse.

(a) WILKES LAND TRAVERSE
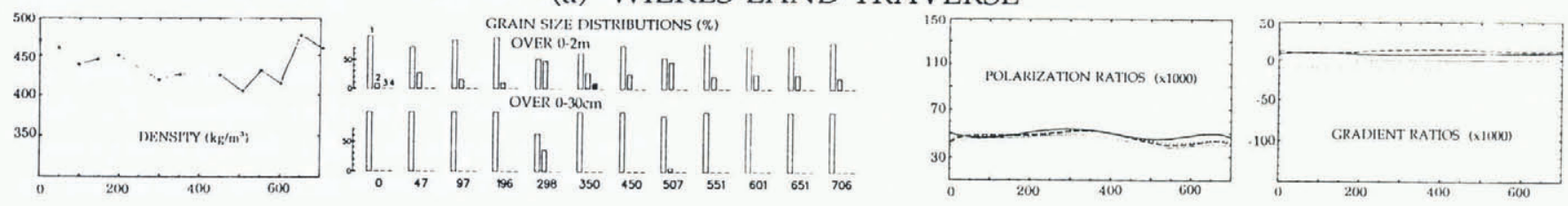

(b) MC MURDO-SOUTH POLE TRAVERSE
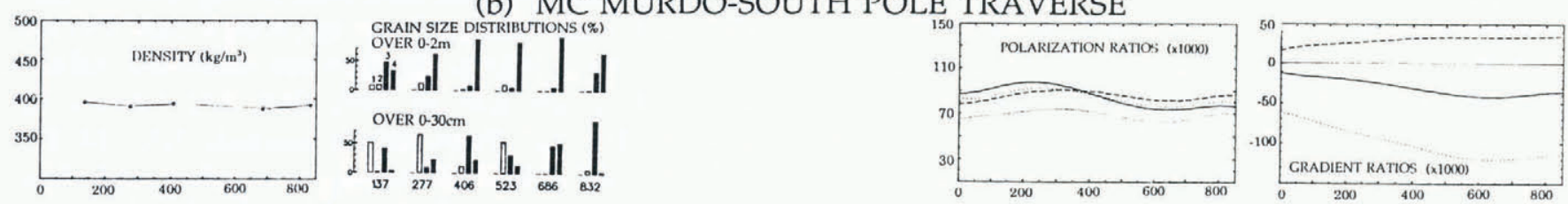

(c) ROSS ICE SHELF TRAVERSE
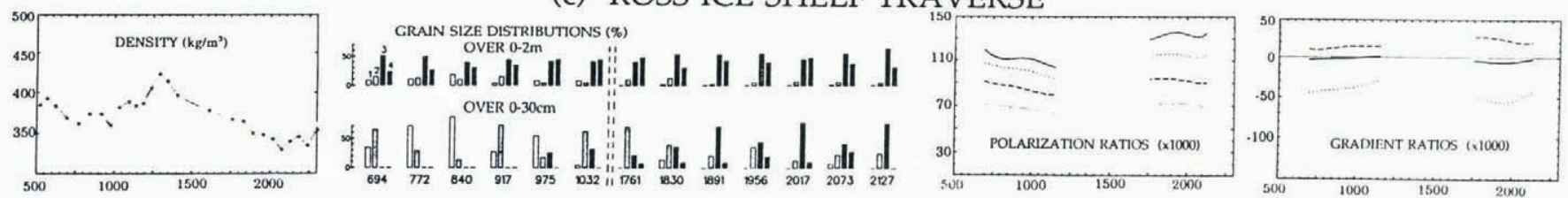

(d) MIRNY-VOSTOK TRAVERSE
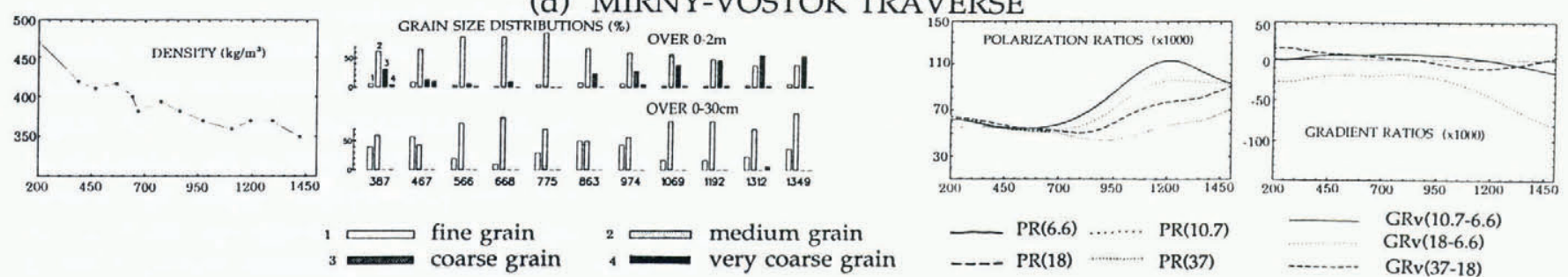

Fig. 4. Density, grain-size distributions, polarization ratios and vertical gradient ratios for the four selected traverses. The horizontal axis expresses the distance from the starting point in $\mathrm{km}$. 


\section{McMurdo-South Pole traverse}

The traverse which links McMurdo with South Pole was undertaken during 1960-61 (Giovinetto, 1963). Our study is limited to the first $850 \mathrm{~km}$ (starting point, $78^{\circ} \mathrm{S}$, $154.2^{\circ} \mathrm{E}$ ) because there are no SMMR data south of $84^{\circ} \mathrm{S}$. Firn temperature fluctuates between $-45^{\circ} \mathrm{C}$ and $-50^{\circ} \mathrm{C}$. Elevation is $2300 \mathrm{~m}$ at the start station, and reaches a maximum of $2800 \mathrm{~km}$ at $850 \mathrm{~km}$. Average density is about $390 \mathrm{~kg} \mathrm{~m}^{-3}$ (Fig. 4b).

Coarse to very coarse snow grains are found, especially after $400 \mathrm{~km}$. This is typical of this traverse. Near the surface $\cdot(0-30 \mathrm{~cm})$, the distribution of grain-size is dominated by the coarse grain-size. Going deeper in the pits $(0-2 \mathrm{~m})$, these coarse grains become very coarse grains. From 0 to $400 \mathrm{~km}$, there is a transition from medium grains to coarse grains (Fig. 4b).

This almost central area is characterized by a weak accumulation rate (about $5-10 \mathrm{~g} \mathrm{~cm}^{-2} \mathrm{a}^{-1}$ (Bromwich, 1988)). This explains the higher number of strata zompared to the Wilkes traverse: 25 to 45 , with an average of 35 strata. A strong temperature gradient nduces snow grain growth to coarse grains (depth hoar). It also produces very strong sublimation effects, so summer layers disappear (Giovinetto, 1963). Moreover, grain growth and wind make the density high. As in the Wilkes region, the wind acts on the surface snow by forming sastrugis and wind crusts.

Polarization ratios are globally slightly higher than for the Wilkes route, about $70-100 \times 10^{-3}$. Except for PR(37), they have only slightly different frequency responses. We can observe an inversion in frequency response at $350-400 \mathrm{~km}$ which may be due to a surface variation (Fig. 4b). Gradient ratios are very extreme, especially $\operatorname{GRv}(18-6.6)$ which reaches the minimum value observed in Antarctica at around $800 \mathrm{~km}$. Only $\operatorname{GRv}(37-18)$ is positive and almost constant all along the route (Fig. 4 b).

\section{Ross Ice Shelf traverse}

The Ross Ice Shelf traverse was made in 1957-58 (Crary and others, 1962). Only the areas where SMMR data are available will be described: (I) from 700 to $1150 \mathrm{~km}$ and (II) from 1750 to $2150 \mathrm{~km}$ (starting point, $78.1^{\circ} \mathrm{S}$, $\left.161.5^{\circ} \mathrm{W}\right)$.

In the two areas, the firn temperature is about $-25^{\circ}$ to $-30^{\circ} \mathrm{C}$, slightly colder in area (II). Elevation is between 50 and $70 \mathrm{~m}$. Density decreases from east to west: from area (I), average density $370 \mathrm{~kg} \mathrm{~m}^{-3}$ to area (II), average density $340 \mathrm{~kg} \mathrm{~m}^{-3}$ (Fig. $4 \mathrm{c}$ ).

Surface grain-size $(0-30 \mathrm{~cm})$ is dominated by finemedium grains in area (I) compared to medium-coarse grains in area (II). Deeper in the pits $(0-2 \mathrm{~m})$ and for both areas, the grains are coarse to very coarse (Fig. $4 \mathrm{c}$ ).

The weak accumulation rate (about $10-15 \mathrm{~g} \mathrm{~cm}^{-2} \mathrm{a}^{-1}$ (Bromwich, 1988)) explains the high number of strata: about $50-60$ strata. The stratigraphy is well structured as follows (Crary and others, 1962):

- winter layer: high density and fine grain snow

- summer layer: weak density, coarse grain snow, and also melting crusts.

Polarization ratios are high in the two areas and increase with decreasing frequency (Fig. 4c). The most noticeable difference between the two areas is shown by $\mathrm{PR}(6.6)$ and $\mathrm{PR}(10.7)$, which are higher in area (II) than in area (I). Gradient ratios present the same configuration as for the McMurdo-South Pole traverse, but with lower intensity (Fig. 4c). GRv(18-6.6) is lower in (II) than in (I) and the opposite is true for $\operatorname{GRv}(37-18)$.

\section{Mirny-Vostok traverse}

The Mirny-Vostok route shows us a transition between two characteristic areas, starting from the coast towards the central plateau (personal communication from Lipenkov and Petit). SMMR data are available between $200 \mathrm{~km}$ and $1440 \mathrm{~km}$.

Firn temperature decreases progressively from $-10^{\circ} \mathrm{C}$ on the coast to $-60^{\circ} \mathrm{C}$ on the central plateau, whereas the elevation increases from sea level to $3500 \mathrm{~m}$ at Vostok Station $(1440 \mathrm{~km})$ going through a maximum of $3550 \mathrm{~m}$ at $1250 \mathrm{~km}$. Density is higher than $420 \mathrm{~kg} \mathrm{~m}^{-3}$ between $200 \mathrm{~km}$ and $600 \mathrm{~km}$ and decreases progressively to lower densities with an average of $360 \mathrm{~kg} \mathrm{~m}^{-3}$ between $1000 \mathrm{~km}$ and $1440 \mathrm{~km}$ (Fig. 4d). Grain-size is fine-medium on the near surface $(0-30 \mathrm{~cm})$, and almost constant all along the traverse, but increases below $(0-2 \mathrm{~m})$ from medium grains at $781 \mathrm{~km}$ to medium-coarse grains at $1340 \mathrm{~km}$ (Fig. $4 \mathrm{~d}$ ).

Accumulation rate decreases from the coast $\left(>40 \mathrm{~g} \mathrm{~cm}^{-2} \mathrm{a}^{-1}\right.$ (Bromwich, 1988)) towards the central plateau ( $<5 \mathrm{~g} \mathrm{~cm}^{-2} \mathrm{a}^{-1}$ (Bromwich, 1988)), inducing a growing number of strata. In the coastal area, the strong accumulation rate and the wind action make the snow fine and compact, whereas on the dome area, the weak accumulation rate, the lower wind and the strong temperature gradient result in grain growth with depth and low density.

Between $200 \mathrm{~km}$ and $700 \mathrm{~km}$, polarization ratios are constant with no distinct frequency response (Fig. 4d). After $700 \mathrm{~km}$ they begin to differ for each frequency. $\mathrm{PR}(6.6)$ and $\mathrm{PR}(10.7)$ increase to reach a maximum on the dome $(1200 \mathrm{~km})$ and then decrease towards Vostok. $\mathrm{PR}$ (18) increases from $800 \mathrm{~km}$ to $1400 \mathrm{~km}$ and $\mathrm{PR}(37)$ from $900 \mathrm{~km}$ to $1400 \mathrm{~km}$. Gradient ratios, between $200 \mathrm{~km}$ and $800 \mathrm{~km}$, are close to zero. Only $\operatorname{GRv}(18-6.6)$ is negative (Fig. 4d). From $800 \mathrm{~km}$ onwards, GRv(37-18) and $\operatorname{GRv}(10.7-6.6)$ evolve slowly to negative values but stay close to zero, whereas $\operatorname{GRv}(18-6.6)$ decreases strongly.

\section{Summary of traverse results}

The absolute firn temperature and its gradient over depth have a twofold influence on the radiometric measurements: first because they modify the snow structure and therefore its emissivity, second because the brightness temperature is proportional to an integrated temperature over depth. As the penetration depth at one single frequency should not depend greatly on the polarization, we assume that the polarization ratios are almost temperature independent. Conversely we have to be careful when analyzing the gradient ratios, even if November data have been chosen because the temperature gradient is minimum at this period.

Two main remarks can be made from the observations. High absolute values of polarization ratios for the 


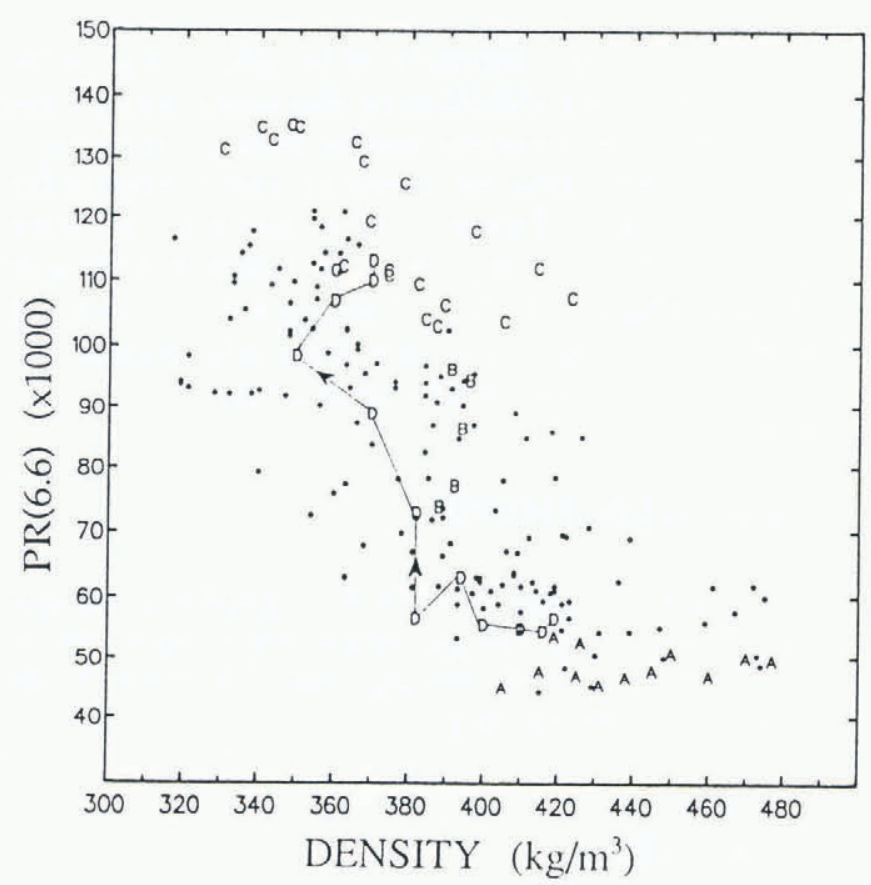

Fig. 5. Representation of the $P R(6.6)$ versus the mean density over 0-2 m: $A$, points for the Wilkes Land traverse; B, points for the McMurdo-South Pole traverse; $C$, points for the Ross Ice Shelf traverse; $D$, points for the Mirny-Vostok traverse; arrows indicate the direction Mirny to Vostok; ., points for other traverses which are not particularly described.

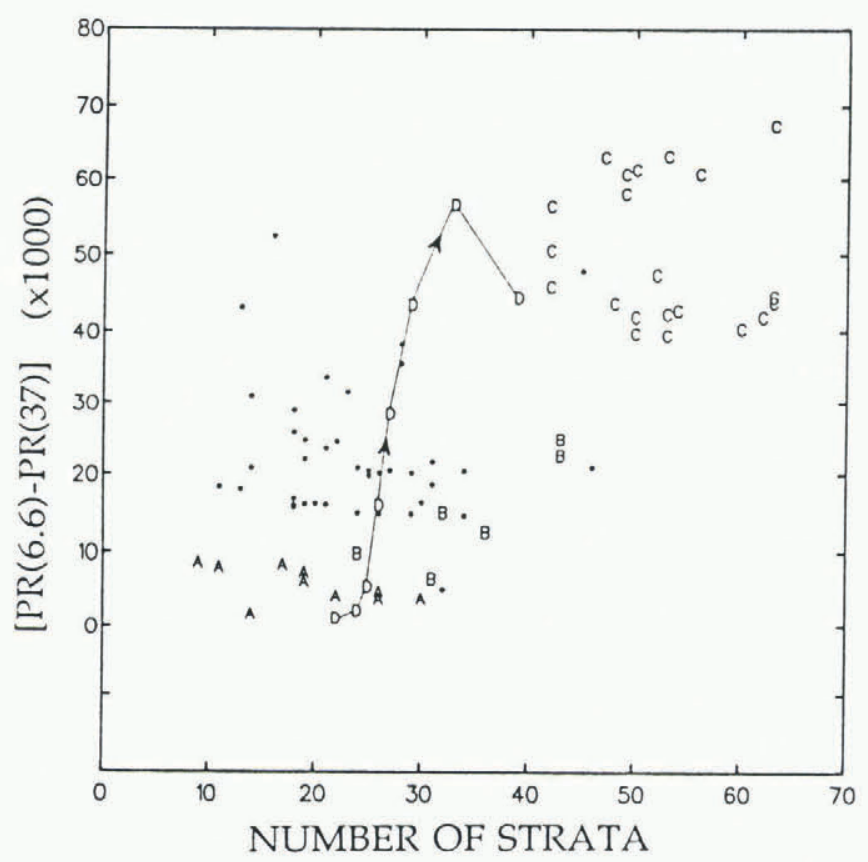

Fig. 6. Representation of the difference [PR(6.6)$P R(37)]$ versus the number of strata. Points signification is the same as for Figure 5.

Table 1. Number of strata and density ranges for the studied traverses

\begin{tabular}{ccc}
\hline Number of strata & Density & Studied traverses \\
& $\mathrm{kg} \mathrm{m}^{-3}$ & \\
& & \\
\hline & $>420$ & A \\
$15-20$ & $>420$ & D, until $600 \mathrm{~km}$ \\
$20-25$ & 390 & B \\
35 & 360 & D, from $1000 \mathrm{~km}$ \\
$35-40$ & 370 & C, part I \\
55 & 340 & C, part II \\
55 & &
\end{tabular}

result contradicts a sensitivity study carried out with a simplified snow emissivity model (Surdyk and Fily, 1991). We suggest that a low density is only a sign of a more stratified snow cover but has not strong direct effect on the emissivity. Our data confirm this result on a large scale (Table 1), even if other processes such as melting should be taken into account on the Ross Ice Shelf, for example. Low density induces low conduction with large thermal gradients and then stratification by diagenesis (Alley, 1988).

On the other hand, a strong correlation was found between the number of strata and the difference between polarization ratios, especially between $\mathrm{PR}(6.6)$ and $P R(37)$. The larger the number of strata, the larger is [PR(6.6)-PR(37)] (see Fig. 6). This is due to the different penetration depth of the two channels. The penetration
We have seen that large polarization ratios occur when the density is low. This is mainly the case for low frequencies such as $6.6 \mathrm{GHz}$ (Fig. 5). This experimental 
depth at $6.6 \mathrm{GHz}(>10 \mathrm{~m})$ is much larger than at $37 \mathrm{GHz}$ (<1 m) (Rott, 1985). That makes the former channel more sensitive to stratification.

More surprisingly, the correlation between $\mathrm{PR}(6.6)$ and the number of strata was not so good. More details should be taken into account when considering a stratum (wind crust, melting crust, snow layer, etc.) and also that the number of strata over $0-2 \mathrm{~m}$ depth is not representative enough for the $6.6 \mathrm{GHz}$ penetration depth.

\section{Gradient ratios and grain-size}

The best correlation was found between the mean grainsize over $0-2 \mathrm{~m}$ and $\mathrm{GRv}(18-6.6)$ : the larger the grains, the smaller GRv(18-6.6) (Fig. 7). Our snow emissivity model shows such strong dependence. Unfortunately no precise conclusion can be drawn from the gradient ratios because of the importance of the unknown temperature profile. It is, for example, clear that a great deal of the variability of the data scatter on Figure 7 could be explained by very different surface temperatures.

\section{CONCLUSIONS}

The aim of this study was to describe observations of the snow from a microwave radiometer compared to ground measurements. The following correlations were found:

- the larger the grain-size, the smaller is the gradient ratio between $6.6 \mathrm{GHz}$ and $18 \mathrm{GHz}$

- the polarization ratio is mainly affected by the stratification of the firn, low frequency are more more affected than high frequency.

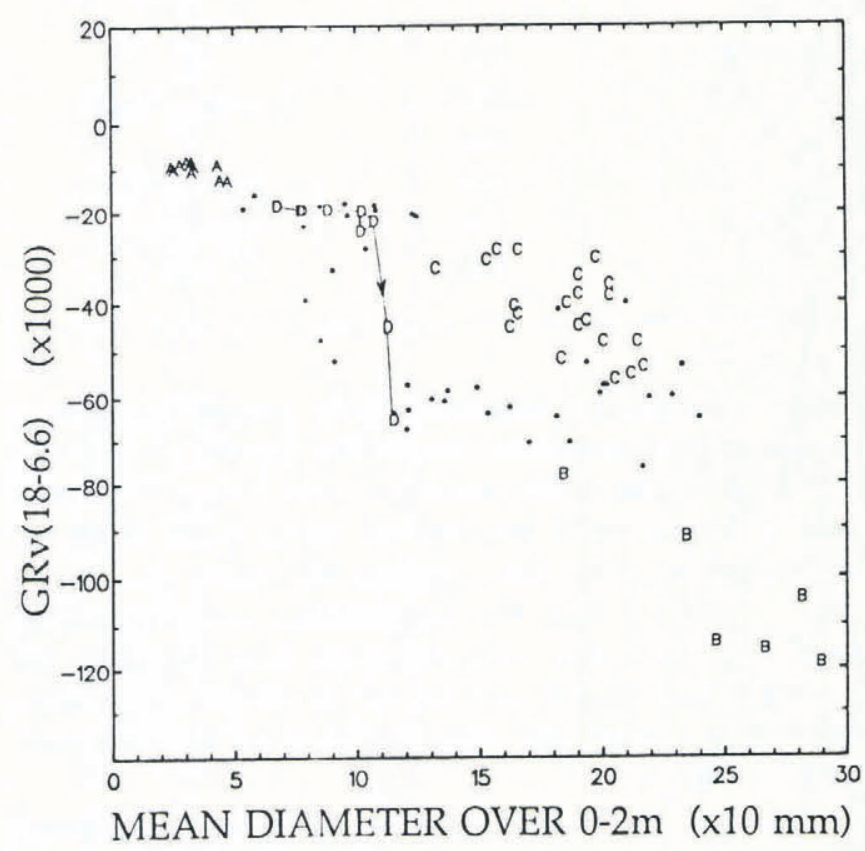

Fig. 7. Representation of the $G R v(18-6.6)$ versus the mean diameter over 0-2 $\mathrm{m}$. Legend the same as for Figure 5.
More studies are necessary to be able to map snow characteristics from SMMR data. The stratification of the snow and the temperature profile must be taken into account in a more detailed fashion in order to explain the scatter of data on Figures 5 to 7. Anyway, the main conclusions of this study should be taken into account when planning field work or building a snow emissivity model, i.e. the great importance of the stratification, the grain-size, and also the temperature profile.

\section{ACKNOWLEDGEMENTS}

This work was funded by ATP Teledetection (Contract 87/CNES/1254). We are grateful to Dr D. Han, Dr P. Gloersen, and Dr P.H. Hwang from NASA/GSFC for providing the SMMR data.

\section{REFERENCES}

Alley, R.B. 1988. Concerning the deposition and diagenesis of strata in polar firn. F. Glaciol., 34(118), 283-290.

Bromwich, D.H. 1988. Snowfall in high southern latitudes. Rev. Geophys., 26(1), 149-168.

Crary, A. P., E.S. Robinson, H. F. Bennett and W. W. Boyd. 1962. Glaciological studies of the Ross Ice Shelf, Antarctica, 1957-1960. IG Y Glaciol. Rep. 6.

Fily, M. and J.-P. Benoist. 1991. Large-scale statistical study of Scanning Multichannel Microwave Radiometer (SMMR) data over Antarctica. f. Glaciol., 37(125), 129-139.

Fu, C. C., D. Han, S. T. Kim and P. Gloersen. 1988. User's guide for the Nimbus 7 Multichannel Microwave Radiometer (SMMR), cell-all tape. Greenbelt, MD, Goddard Space Flight Center. (NASA Reference Publication 1210.)

Giovinetto, M.B. 1963. Glaciological studies on the McMurdo-South Pole traverse, 1960-1961. Ohio State Univ. Inst. Polar Stud. Rep. 7.

Goodwin, I.D. 1988a. Firn core data from shallow drilling investigation in eastern Wilkes Land, East Antarctica. ANARE Res. Notes 65.

Goodwin, I. D. 1988b. Ice sheet topography and surface characteristics in eastern Wilkes Land, East Antarctica. ANARE Res. Notes 64.

Rott, H., G. Domik, C. Mätzler, H. Miller and K. G. Lenhart. 1985. Study on use and characteristics of SAR for land snow and ice applications. European Space Agency Contract Report CR(P)2168.

Syrdyk, $\dot{\text { S}}$. and M. M. Fily. 1991. Comparison between the observed microwave spectral signatures over the Antarctic ice sheet and a snow emissivity model. Colloque "Physical Measurements and Signatures in Remote Sensing, Courchevel, France, 14-18 Jan. 1991." European Space Agency Special Publication 319, 351-354.
The accuracy of references in the text and in this list is the responsibility of the authors, to whom queries should be addressed. 